International Journal of Soft Computing 6(4): 111-118, 2011

ISSN: 1816-9503

(C) Medwell Journals, 2011

\title{
Anti-Synchronization of Lu and Pan Chaotic Systems by Adaptive Nonlinear Control
}

\author{
${ }^{1} \mathrm{~V}$. Sundarapandian and ${ }^{2} \mathrm{R}$. Karthikeyan \\ ${ }^{1}$ Department of Systems and Control Engineering, Research and Development Center \\ ${ }^{2}$ Department of Electronics and Instrumentation Engineering, \\ Vel Tech Dr. R.R. and S.R. Technical University, Avadi, 600-062 Chennai, Tamil Nadu, India
}

\begin{abstract}
In this study, researchers apply control method to derive new results for the anti-synchronization of identical uncertain Lu systems, identical uncertain Pan systems and non-identical Lu and uncertain Pan systems. In adaptive anti-synchronization of identical chaotic systems, the parameters of the master and slave systems are unknown and we devise feedback control laws using estimates of the system parameters. In adaptive anti-synchronization of non-identical chaotic systems, the parameters of the master system are known but the parameters of the slave systems are unknown and we devise feedback control laws using the estimates of the parameters of the slave system. The adaptive anti-synchronization results derived in this study for uncertain Lu and Pan systems are established using Lyapunov stability theory. Since, the Lyapunov exponents are not required for these calculations, the adaptive control method is very effective and convenient to achieve anti-synchronization of identical and non-identical Lu and Pan chaotic systems. Numerical simulations are given to demonstrate the effectiveness of the proposed adaptive anti-synchronization schemes for the uncertain chaotic systems addressed in this study.
\end{abstract}

Key words: Anti-synchronization, chaos, adaptive control, Lu system, pan system, India

\section{INTRODUCTION}

Chaotic systems are nonlinear dynamical systems that are highly sensitive to initial conditions. This sensitivity is popularly known as the butterfly effect (Alligood et al., 1997). In 1963, Lorenz (Pecora and Carroll, 1990) obtained the first chaotic system when he was studying the weather patterns. Chaos is an interesting nonlinear phenomenon and has been extensively studied in the last four decades.

Chaos theory has been applied in many scientific and engineering disciplines such as Physics, Mathematics, Economics, Computer Science, Economics, Electrical Engineering, Communication Engineering, Biology, Microbiology, Robotics, etc.

Since, the pioneering study by Pecora and Carroll (1990) chaos synchronization problem has been studied extensively and intensively in the literature (Carroll and Pecora, 1991; Sundarapandian, 2011a). Chaos theory has been applied to a variety of fields such as physical systems (Lakshmanan and Murali, 1996), chemical systems (Han et al., 1995) ecological systems (Blasius et al., 1999), secure communications (Murali and Lakshmanan, 1998; Kocarev and Parlitz, $1995)$ etc.

In the last two decades, various schemes have been successively applied for chaos synchronization such as PC method (Carroll and Pecora, 1991), OGY method (Ott et al., 1990), active control (Agiza and Yassen, 2001; Huang et al., 2004; Sundarapandian, 2011b), adaptive control (Liao and Tsai, 2000; Zhang and Zhu, 2008), time delay feedback approach (Park and Kwon, 2003), backstepping design method (Yu and Zhang, 2006) sampled-data feedback method (Yang and Chua, 1999), sliding mode control (Konishi et al., 1998; Sundarapandian, 2011c), etc.

In most of the chaos synchronization approaches, the master-slave or drive-response formalism is used. If a particular chaotic system is called the master or drive system and another chaotic system is called the slave or response system, then the goal of anti-synchronization is to use the output of the master system to control the slave system so, that the sum of the outputs of the slave and master systems decays to zero asymptotically.

In this study, researchers apply adaptive control method to derive new results for the anti-synchronization of identical Lu systems (Lu and Chen, 2002), identical Pan systems (Pan et al., 2010) and non-identical Lu and Pan chaotic systems.

In adaptive anti-synchronization of identical chaotic systems, the parameters of the master and slave systems are unknown and researchers devise feedback control laws using estimates of the system parameters. In

Corresponding Author: V. Sundarapandian, Department of Systems and Control Engineering, Research and Development Center, Vel Tech Dr. R.R. and S.R. Technical University, Avadi, 600-062 Chennai, Tamil Nadu, India 
adaptive anti-synchronization of different chaotic systems, the parameters of the master system are known but the parameters of the slave system are unknown and researchers devise feedback control laws using the estimates of the parameters of the slave system.

\section{ADAPTIVE ANTI-SYNCHRONIZATION OF DENTICAL LU CHAOTIC SYSTEMS}

Theoretical results: In this study, researchers discuss the adaptive anti-synchronization of identical Lu systems (Lu and Chen, 2002) where the parameters of the master and slave systems are unknown. As the master system, researchers consider the Lu dynamics described by:

Where:

$$
\begin{aligned}
& \dot{\mathrm{x}}_{1}=\mathrm{a}\left(\mathrm{x}_{2}-\mathrm{x}_{1}\right) \\
& \dot{\mathrm{x}}_{2}=\left(-\mathrm{x}_{1} \mathrm{x}_{3}+\mathrm{cx}_{2}\right) \\
& \dot{\mathrm{x}}_{3}=\left(\mathrm{x}_{1} \mathrm{x}_{2}-\mathrm{bx}_{3}\right)
\end{aligned}
$$

$\mathrm{x}_{1}, \mathrm{x}_{2}, \mathrm{x}_{3}=$ State variables

$\mathrm{a}, \mathrm{b}, \mathrm{c}=$ Unknown parameters of the system

As the slave system, researchers consider the controlled Lu dynamics described by:

Where:

$$
\begin{aligned}
& \dot{\mathrm{y}}_{1}=\mathrm{a}\left(\mathrm{y}_{2}-\mathrm{y}_{1}\right)+\mathrm{u}_{1} \\
& \dot{\mathrm{y}}_{2}=-\mathrm{y}_{1} \mathrm{y}_{3}+\mathrm{cy}_{2}+\mathrm{u}_{2} \\
& \dot{\mathrm{y}}_{3}=\mathrm{y}_{1} \mathrm{y}_{2}-\mathrm{by}_{3}+\mathrm{u}_{3}
\end{aligned}
$$

$\mathrm{y}_{1}, \mathrm{y}_{2}, \mathrm{y}_{3}=$ State variables

$\mathrm{u}_{1}, \mathrm{u}_{2}, \mathrm{u}_{3}=$ Nonlinear controls to be designed

The Lu system (1) is chaotic when the parameter values are; $a=36, b=3$ and $c=20$. The state orbits of the Lu system are shown in Fig. 1.

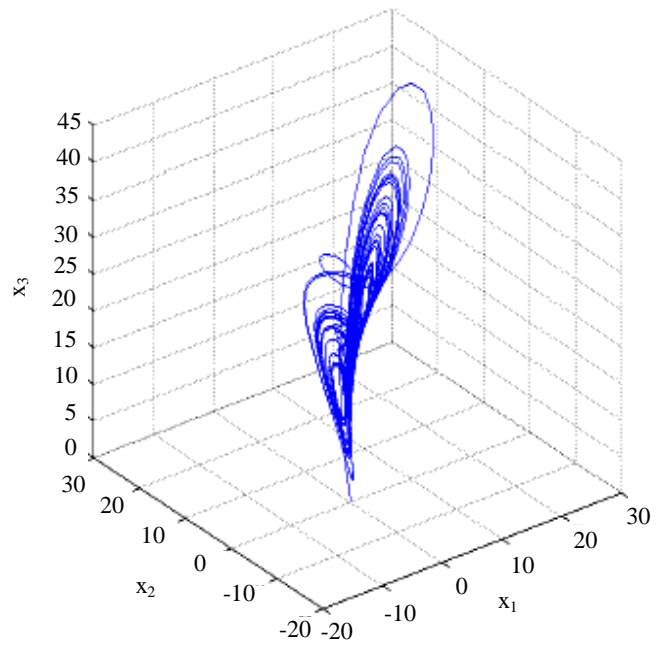

Fig. 1: State orbits of the Lu system
The anti-synchronization error e is defined by:

$$
\begin{aligned}
& e_{1}=y_{1}+x_{1} \\
& e_{2}=y_{2}+x_{2} \\
& e_{3}=y_{3}+x_{3}
\end{aligned}
$$

The error dynamics is easily obtained as:

$$
\begin{aligned}
& \dot{\mathrm{e}}_{1}=\mathrm{a}\left(\mathrm{e}_{2}-\mathrm{e}_{1}\right)+\mathrm{u}_{1} \\
& \dot{\mathrm{e}}_{2}=-\mathrm{y}_{1} \mathrm{y}_{3}-\mathrm{x}_{1} \mathrm{x}_{3}+\mathrm{ce}_{2}+\mathrm{u}_{2} \\
& \dot{\mathrm{e}}_{3}=\mathrm{y}_{1} \mathrm{y}_{2}+\mathrm{x}_{1} \mathrm{x}_{2}-\mathrm{be}_{3}+\mathrm{u}_{3}
\end{aligned}
$$

Let us now define the adaptive control functions $\mathrm{u}_{1}$ $(\mathrm{t}), \mathrm{u}_{2}(\mathrm{t})$ and $3 \mathrm{u}_{3}(\mathrm{t})$ as:

$$
\begin{aligned}
& \mathrm{u}_{1}(t)=\hat{\mathrm{a}}\left(\mathrm{e}_{2}-\mathrm{e}_{1}\right)-\mathrm{k}_{1} \mathrm{e}_{1} \\
& \mathrm{u}_{2}(t)=\mathrm{y}_{1} \mathrm{y}_{3}+\mathrm{x}_{1} \mathrm{x}_{2}-\hat{\mathrm{c}} \mathrm{e}_{2}-\mathrm{k}_{2} \mathrm{e}_{2} \\
& \mathrm{u}_{3}(t)=\mathrm{y}_{1} \mathrm{y}_{2}-\mathrm{x}_{1} \mathrm{x}_{2}+\hat{b} \mathrm{e}_{3}-\mathrm{k}_{3} \mathrm{e}_{3}
\end{aligned}
$$

where, $\hat{a}, \hat{b}$ and $\hat{c}$ are estimates of a and $c$, respectively and $k_{i},(i=1,2,3)$ are positive constants. Substituting Eq. 5 into Eq. 4 the error dynamics simplifies to:

$$
\begin{aligned}
& \dot{\mathrm{e}}_{1}=(\mathrm{a}-\hat{\mathrm{a}})\left(\mathrm{e}_{2}-\mathrm{e}_{1}\right)-\mathrm{k}_{1} \mathrm{e}_{1} \\
& \dot{\mathrm{e}}_{2}=(\mathrm{c}-\hat{\mathrm{c}}) \mathrm{e}_{2}-\mathrm{k}_{2} \mathrm{e}_{2} \\
& \dot{\mathrm{e}}_{3}=-(\mathrm{b}-\hat{\mathrm{b}}) \mathrm{e}_{3}-\mathrm{k}_{3} \mathrm{e}_{3}
\end{aligned}
$$

Let us now define the parameter errors as:

$$
\begin{aligned}
& e_{a}=a-\hat{a} \\
& e_{b}=b-\hat{b} \\
& e_{c}=c-\hat{c}
\end{aligned}
$$

Substituting Eq. 7 into Eq. 6, researchers obtain the error dynamics:

$$
\begin{aligned}
& \dot{\mathrm{e}}_{1}=\mathrm{e}_{\mathrm{a}}\left(\mathrm{e}_{2}-\mathrm{e}_{1}\right)-\mathrm{k}_{1} \mathrm{e}_{1} \\
& \dot{\mathrm{e}}_{2}=\mathrm{e}_{\mathrm{c}} \mathrm{e}_{2}-\mathrm{k}_{2} \mathrm{e}_{2} \\
& \dot{\mathrm{e}}_{3}=-\mathrm{e}_{\mathrm{b}} \mathrm{e}_{3}-\mathrm{k}_{3} \mathrm{e}_{3}
\end{aligned}
$$

For the derivation of the update law for adjusting the estimates of the parameters, the Lyapunov approach is used. Researchers consider the quadratic Lyapunov function defined by:

$$
\mathrm{V}=\frac{1}{2}\left(\mathrm{e}_{1}^{2}+\mathrm{e}_{2}^{2}+\mathrm{e}_{3}^{2}+\mathrm{e}_{\mathrm{a}}^{2}+\mathrm{e}_{\mathrm{b}}^{2}+\mathrm{e}_{\mathrm{c}}^{2}\right)
$$

Which is a positive definite function on $\mathrm{R}^{6}$. Researchers also note that: 
Int. J. Soft Comput., 6 (4): 111-118, 2011

$$
\begin{aligned}
& \dot{\mathrm{e}}_{\mathrm{a}}=-\dot{\hat{\mathrm{a}}} \\
& \dot{\mathrm{e}}_{\mathrm{b}}=-\hat{\hat{\mathrm{b}}} \\
& \dot{\mathrm{e}}_{\mathrm{c}}=-\dot{\hat{\mathrm{c}}}
\end{aligned}
$$

Differentiating Eq. 9 along the trajectories of Eq. 8 and using Eq. 10, we obtain:

$$
\begin{aligned}
\dot{\mathrm{V}}= & -\mathrm{k}_{1} \mathrm{e}_{1}^{2} \mathrm{k}_{2} \mathrm{e}_{2}^{2}-\mathrm{k}_{3} \mathrm{e}_{3}^{2}+\mathrm{e}_{\mathrm{a}}\left[\mathrm{e}_{1}\left(\mathrm{e}_{2}-\mathrm{e}_{1}\right)-\dot{\hat{\mathrm{a}}}\right] \\
& +\mathrm{e}_{\mathrm{b}}\left[-\mathrm{e}_{3}^{\mathrm{e}}-\dot{\hat{\mathrm{b}}}\right]+\mathrm{e}_{\mathrm{c}}\left[\mathrm{e}_{2}^{\mathrm{e}}-\dot{\hat{\mathrm{c}}}\right]
\end{aligned}
$$

In view of Eq. 11 the estimated parameters are updated by the following law:

$$
\begin{aligned}
& \dot{\hat{\mathrm{a}}}=\mathrm{e}_{1}\left(\mathrm{e}_{2}-\mathrm{e}_{1}\right)+\mathrm{k}_{4} \mathrm{e}_{\mathrm{a}} \\
& \dot{\hat{\mathrm{b}}}=-\mathrm{e}_{3}^{2}+\mathrm{k}_{5} \mathrm{e}_{\mathrm{b}} \\
& \dot{\hat{\mathrm{c}}}=\mathrm{e}_{2}^{2}+\mathrm{k}_{6} \mathrm{e}_{\mathrm{c}}
\end{aligned}
$$

where, $\mathrm{k}_{4}-\mathrm{k}_{6}$ are positive constants. Substituting Eq. 12 into Eq. 11, we get:

$$
\dot{\mathrm{V}}=-\mathrm{k}_{1} \mathrm{e}_{1}^{2}-\mathrm{k}_{2} \mathrm{e}_{2}^{2}-\mathrm{k}_{3} \mathrm{e}_{3}^{2}-\mathrm{k}_{4} \mathrm{e}_{\mathrm{a}}^{2}-\mathrm{k}_{5} \mathrm{e}_{\mathrm{b}}^{2}-\mathrm{k}_{6} \mathrm{e}_{\mathrm{c}}^{2}
$$

Which is a negative definite function on $\mathrm{R}^{6}$. Thus, by Lyapunov stability theory (Hahn, 1967) it is immediate that the anti-synchronization error and parameter estimation error decay to zero exponentially with time. Hence, researchers have proved the result.

Theorem 1: The identical Lu systems 1 and 2 with unknown parameters are globally and exponentially anti- synchronized by the adaptive control law 5 where the update law for the parameter estimates is given by Eq. 11 and $\mathrm{k}_{\mathrm{i}}, \mathrm{i}=1, \ldots, 6$ are positive constants.

Numerical results: For the numerical simulations, the fourth-order Runge-Kutta method with time-step $h=10^{-6}$ is used to solve the Lu chaotic systems 1 and 2 with the adaptive control law 5 and the parameter update law Eq. 11 using MATLAB. For the Lu chaotic systems 1 and 2 the parameter values are taken as those which result in the chaotic behaviour of the systems, viz.

$$
\mathrm{a}=36, \mathrm{~b}=3 \text { and } \mathrm{c}=20
$$

Suppose that the initial values of the parameter estimates are:

$$
\hat{a}(0)=10, \hat{b}(0)=6 \text { and } \hat{c}(0)=12
$$
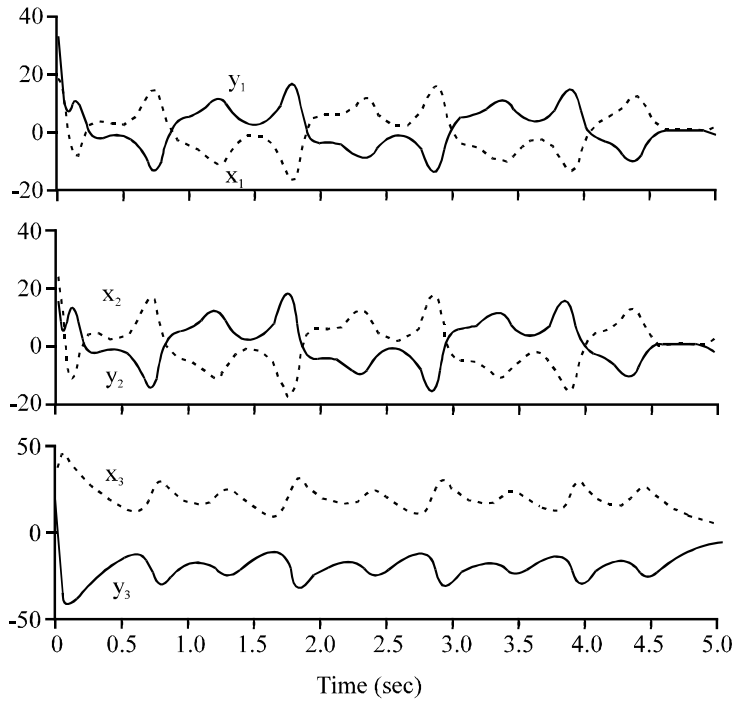

Fig. 2: Anti-synchronization of the identical Lu system

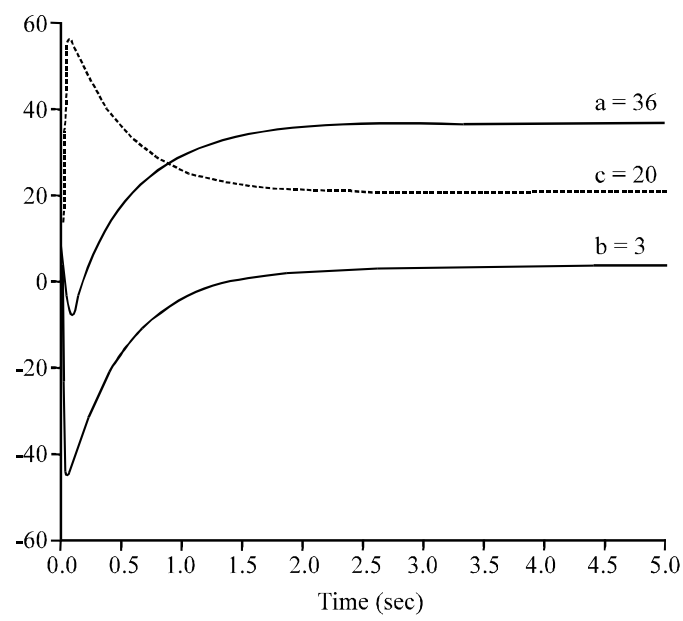

Fig. 3: Parameter estimates â(t), $\hat{b}(t), \hat{c}(t)$

Suppose that the gain values are taken as:

$$
\mathrm{k}_{\mathrm{i}}=2 \text { for } \mathrm{i}=1,2, \ldots, 6
$$

The initial values of the master system (Eq. 1) are taken as:

$$
x_{1}(0)=12, x_{2}(0)=25, x_{3}=(0)=36
$$

The initial values of the slave system (Eq. 2) are taken as:

$$
\mathrm{y}_{1}(0)=35, \mathrm{y}_{2}(0)=15, \mathrm{y}_{3}(0)=18
$$

Figure 2 shows the anti-synchronization of the identical Lu systems 1 and 2. Figure 3 shows that the estimated values of the parameters $\hat{a}, \hat{b}$ and $\hat{c}$ converge to the system parameters, $\mathrm{a}=36, \mathrm{~b}=3$ and $\mathrm{c}=20$, respectively. 


\section{ADAPTIVE ANTI-SYNCHRONIZATION OF IDENTICAL PAN CHAOTIC SYSTEMS}

Theoretical results: In this study, researchers discuss the adaptive anti-synchronization of identical Pan systems (Pan et al., 2010) where the parameters of the master and slave systems are unknown. As the master system, researchers consider the Pan dynamics described by:

Where:

$$
\begin{aligned}
& \dot{\mathrm{x}}_{1}=\alpha\left(\mathrm{x}_{2}-\mathrm{x}_{1}\right) \\
& \dot{\mathrm{x}}_{2}=\gamma \mathrm{x}_{1}-\mathrm{x}_{1} \mathrm{x}_{3} \\
& \dot{\mathrm{x}}_{3}=\mathrm{x}_{1} \mathrm{x}_{2}-\beta \mathrm{x}_{3}
\end{aligned}
$$

$\mathrm{x}_{1}, \mathrm{x}_{2}, \mathrm{x}_{3}=$ State variables

$\alpha, \beta, \gamma=$ Unknown parameters of the system

The Pan system 14 is chaotic when the parameter values are $\alpha=10, \beta=8 / 3$ and $\gamma=16$. The state orbits of the chaotic Pan system are shown in Fig. 4. As the slave system, researchers consider the controlled Pan dynamics described by:

Where:

$$
\begin{aligned}
& \dot{\mathrm{y}}_{1}=\alpha\left(\mathrm{y}_{2}-\mathrm{y}_{1}\right)+\mathrm{u}_{1} \\
& \dot{\mathrm{y}}_{2}=\gamma \mathrm{y}_{1}-\mathrm{y}_{1} \mathrm{y}_{3}+\mathrm{u}_{2} \\
& \dot{\mathrm{y}}_{3}=\mathrm{y}_{1} \mathrm{y}_{2}-\beta \mathrm{y}_{3}+\mathrm{u}_{3}
\end{aligned}
$$

$\mathrm{y}_{1}, \mathrm{y}_{2}, \mathrm{y}_{3}=$ State variables

$\mathrm{u}_{1}, \mathrm{u}_{2}, \mathrm{u}_{3}=$ Nonlinear controls to be designed

The anti-synchronization error $\mathrm{e}$ is defined by:

$$
\mathrm{e}_{\mathrm{i}}=\mathrm{y}_{\mathrm{i}}+\mathrm{x}_{\mathrm{i}}, \quad \mathrm{i}=1,2,3
$$

The error dynamics is easily obtained as:

$$
\begin{aligned}
& \dot{\mathrm{e}}_{1}=\alpha\left(\mathrm{e}_{2}-\mathrm{e}_{1}\right)+\mathrm{u}_{1} \\
& \dot{\mathrm{e}}_{2}=\gamma \mathrm{e}_{1}-\mathrm{y}_{1} \mathrm{y}_{3}-\mathrm{x}_{1} \mathrm{x}_{3}+\mathrm{u}_{2} \\
& \dot{\mathrm{e}}_{3}=-\beta \mathrm{e}_{3}+\mathrm{y}_{1} \mathrm{y}_{2}+\mathrm{x}_{1} \mathrm{x}_{2}+\mathrm{u}_{3}
\end{aligned}
$$

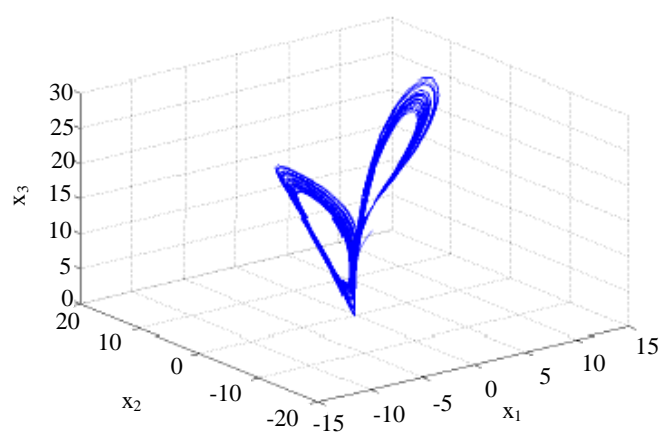

Fig. 4: State orbits of the Pan system
Let us now define the adaptive control functions $\mathrm{u}_{1}(\mathrm{t}), \mathrm{u}_{2}(\mathrm{t})$ and $\mathrm{u}_{3}(\mathrm{t})$ as:

$$
\begin{aligned}
& \mathrm{u}_{1}(\mathrm{t})=-\hat{\alpha}\left(\mathrm{e}_{2}-\mathrm{e}_{1}\right)-\mathrm{k}_{1} \mathrm{e}_{1} \\
& \mathrm{u}_{2}(\mathrm{t})=-\hat{\gamma} \mathrm{e}_{1}+\mathrm{y}_{1} \mathrm{y}_{3}+\mathrm{x}_{1} \mathrm{x}_{3}-\mathrm{k}_{2} \mathrm{e}_{2} \\
& \mathrm{u}_{3}(\mathrm{t})=-\hat{\beta} \mathrm{e}_{3}-\mathrm{y}_{1} \mathrm{y}_{2}-\mathrm{x}_{1} \mathrm{x}_{2}+\mathrm{k}_{3} \mathrm{e}_{3}
\end{aligned}
$$

where, $\hat{\alpha}, \hat{\beta}$ and $\hat{\gamma}$ estimates of $\alpha, \beta$ and $\gamma$, respectively and $\mathrm{k}_{\mathrm{i}}, \mathrm{i}=1,2,3$ are positive constants. Substituting Eq. 18 into Eq. 17 the error dynamics simplifies to:

$$
\begin{aligned}
& \dot{\mathrm{e}}_{1}=(\alpha-\hat{\alpha})\left(\mathrm{e}_{2}-\mathrm{e}_{1}\right)-\mathrm{k}_{1} \mathrm{e}_{1} \\
& \dot{\mathrm{e}}_{2}=(\gamma-\hat{\gamma}) \mathrm{e}_{1}-\mathrm{k}_{2} \mathrm{e}_{2} \\
& \dot{\mathrm{e}}_{3}=(\beta-\hat{\beta}) \mathrm{e}_{3}-\mathrm{k}_{3} \mathrm{e}_{3}
\end{aligned}
$$

Let us now define the parameter errors as:

$$
\begin{aligned}
& e_{\alpha}=\alpha-\hat{\alpha} \\
& e_{\beta}=\beta-\hat{\beta} \\
& e_{\gamma}=\gamma-\hat{\gamma}
\end{aligned}
$$

Substituting Eq. 20 into Eq. 19, researchers obtain the error dynamics:

$$
\begin{aligned}
& \dot{\mathrm{e}}_{1}=\mathrm{e}_{\alpha}\left(\mathrm{e}_{2}-\mathrm{e}_{1}\right)-\mathrm{k}_{1} \mathrm{e}_{1} \\
& \dot{\mathrm{e}}_{2}=\mathrm{e}_{\mathrm{\gamma}} \mathrm{e}_{1}-\mathrm{k}_{2} \mathrm{e}_{2} \\
& \dot{\mathrm{e}}_{3}=-\mathrm{e}_{\beta} \mathrm{e}_{3}-\mathrm{k}_{3} \mathrm{e}_{3}
\end{aligned}
$$

For the derivation of the update law for adjusting the estimates of the parameters, the Lyapunov approach is used. Researchers consider the quadratic Lyapunov function defined by:

$$
\mathrm{V}=\frac{1}{2}\left(\mathrm{e}_{1}^{2}+\mathrm{e}_{2}^{2}+\mathrm{e}_{3}^{2}+\mathrm{e}_{\alpha}^{2}+\mathrm{e}_{\beta}^{2}+\mathrm{e}_{\mathrm{\gamma}}^{2}\right)
$$

Which is a positive definite function on $\mathrm{R}^{6}$ researchers also note that:

$$
\begin{aligned}
& \dot{\mathrm{e}}_{\alpha}=-\dot{\hat{\alpha}} \\
& \dot{\mathrm{e}}_{\beta}=-\dot{\hat{\hat{\beta}}} \\
& \dot{\mathrm{e}}_{\gamma}=-\hat{\hat{\gamma}}
\end{aligned}
$$

Differentiating Eq. 22 along the trajectories of Eq. 21 and using Eq. 23, researchers obtain:

$$
\begin{aligned}
\dot{\mathrm{V}}= & -\mathrm{k}_{1} \mathrm{e}_{1}^{2}-\mathrm{k}_{2} \mathrm{e}_{2}^{2}-\mathrm{k}_{3} \mathrm{e}_{3}^{2}+\mathrm{e}_{\alpha}\left[\mathrm{e}_{1}\left(\mathrm{e}_{2}-\mathrm{e}_{1}\right)-\dot{\hat{\alpha}}\right] \\
& +\mathrm{e}_{\beta}\left[-\mathrm{e}_{3}^{2}-\hat{\hat{\beta}}\right]+\mathrm{e}_{\gamma}\left[\mathrm{e}_{1} \mathrm{e}_{2}-\dot{\hat{\gamma}}\right]
\end{aligned}
$$


In view of Eq. 24, the estimated parameters are updated by the following law:

$$
\begin{aligned}
& \dot{\hat{\alpha}}=\mathrm{e}_{1}\left(\mathrm{e}_{2}-\mathrm{e}_{1}\right)+\mathrm{k}_{4} \mathrm{e}_{\alpha} \\
& \dot{\hat{\beta}}=-\mathrm{e}_{3}^{2}+\mathrm{k}_{5} \mathrm{e}_{\beta} \\
& \dot{\hat{\gamma}}=\mathrm{e}_{1} \mathrm{e}_{2}+\mathrm{k}_{6} \mathrm{e}_{\gamma}
\end{aligned}
$$

where, $\mathrm{k}_{4}, \mathrm{k}_{5}$ and $\mathrm{k}_{6}$ are positive constants. Substituting Eq. 25 into Eq. 24, researchers get:

$$
\dot{\mathrm{V}}=-\mathrm{k}_{1} \mathrm{e}_{1}^{2}-\mathrm{k}_{2} \mathrm{e}_{2}^{2}-\mathrm{k}_{3} \mathrm{e}_{3}^{2}-\mathrm{k}_{4} \mathrm{e}_{\alpha}^{2}-\mathrm{k}_{5} \mathrm{e}_{\beta}^{2}-\mathrm{k}_{6} \mathrm{e}_{\gamma}^{2}
$$

Which is a negative definite function on $\mathrm{R}^{6}$. Thus, by Lyapunov stability theory (Hahn, 1967) it is immediate that the anti-synchronization error and parameter estimation error decay to zero exponentially with time. Hence, researchers have proved the following result.

Theorem 2: The identical Pan systems 14 and 15 with unknown parameters are globally and exponentially antisynchronized by the adaptive control law 18 where the update law for the parameter estimates is given by Eq. 25 and $\mathrm{k}_{\mathrm{i}}, \mathrm{i}=1, \ldots, 6$ are positive constants.

Numerical results: For the numerical simulations, the fourth-order Runge-Kutta method with time-step $\mathrm{h}=10^{-6}$ is used to solve the chaotic systems 14 and 15 with the adaptive control law 18 and the parameter update law (Eq. 25) using MATLAB. For the chaotic systems 14 and 15 , the parameter values are taken as those which result in the chaotic behaviour of the systems, viz:

$$
\alpha=10, \beta=8 / 3 \text { and } \gamma=16
$$

Suppose that the initial values of the parameter estimates are:

$$
\hat{\alpha}(0)=8, \hat{\beta}(0)=12 \text { and } \hat{\gamma}(0)=2
$$

Suppose that the gain values are taken as:

$$
\mathrm{k}_{\mathrm{i}}=2 \text { for } \mathrm{i}=1,2, \ldots, 6
$$

The initial values of the master system (14) are taken as:

$$
x_{1}(0)=18, x_{2}(0)=12, x_{3}(0)=36
$$

The initial values of the slave system (15) are taken as:

$$
\mathrm{y}_{1}(0)=10, \mathrm{y}_{2}(0)=25, \mathrm{y}_{3}(0)=20
$$
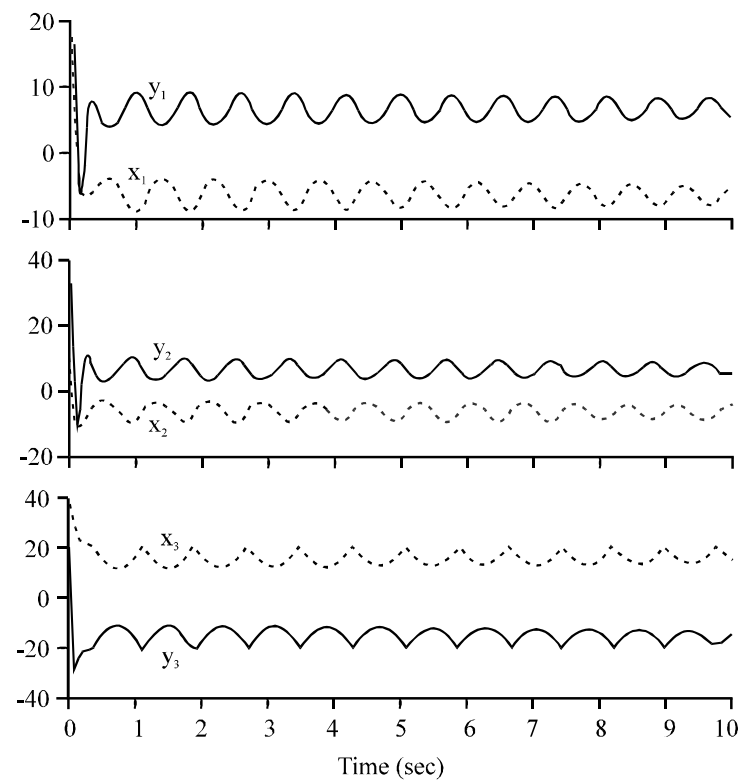

Fig. 5: Anti-synchronization of identical Pan syatem

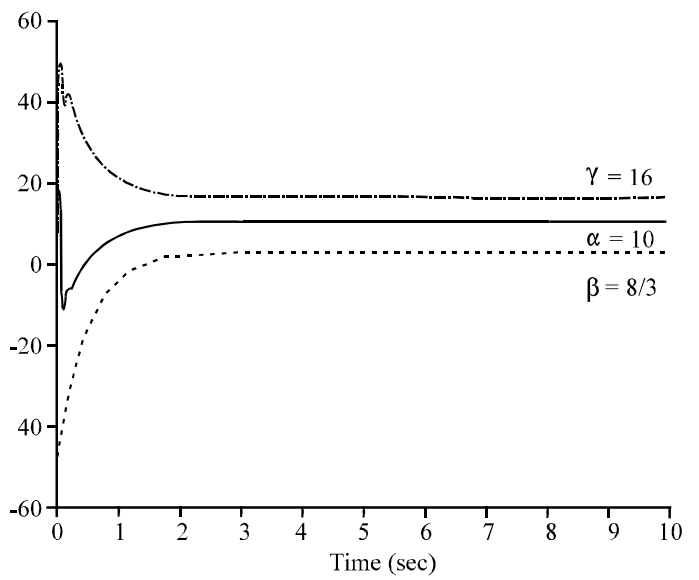

Fig. 6: Parameter estimates $\hat{\alpha}(t), \hat{\beta}(t), \hat{\gamma}(t)$

Figure 5 shows the anti-synchronization of the identical Pan systems 14 and 15. Figure 6 shows that the estimated values of the parameters $\hat{\alpha}, \hat{\beta}$ and $\hat{\gamma}$ converge to the system parameters $\alpha=10, \beta=8 / 3$ and $\gamma=16$, respectively.

\section{ADAPTIVE ANTI-SYNCHRONIZATION OF NON- IDENTICAL LU AND PAN CHAOTIC SYSTEMS}

Theoretical results: In this study, researchers discuss the adaptive anti-synchronization of non-identical Lu and Pan systems. Here, researchers consider the Lu system ( $\mathrm{Lu}$ and Chen, 2002) as the master system whose parameters are known. We consider the controlled Pan 
system (Pan et al., 2010) as the slave system, whose parameters are unknown. As the master system, researchers consider the Lu dynamics described by:

$$
\begin{aligned}
& \dot{\mathrm{x}}_{1}=\mathrm{a}\left(\mathrm{x}_{2}-\mathrm{x}_{1}\right) \\
& \dot{\mathrm{x}}_{2}=-\mathrm{x}_{1} \mathrm{x}_{3}+\mathrm{cx}_{2} \\
& \dot{\mathrm{x}}_{3}=\mathrm{x}_{1} \mathrm{x}_{2}-\mathrm{bx}_{3}
\end{aligned}
$$

where, $\mathrm{x}_{1}-\mathrm{x}_{3}$ are the state variables and a-c are known parameters of the system. As the slave system, researchers consider the controlled Pan dynamics described by:

$$
\begin{aligned}
& \dot{\mathrm{y}}_{1}=\alpha\left(\mathrm{y}_{2}-\mathrm{y}_{1}\right)+\mathrm{u}_{1} \\
& \dot{\mathrm{y}}_{2}=\gamma_{1}-\mathrm{y}_{1} \mathrm{y}_{3}+\mathrm{u}_{2} \\
& \dot{\mathrm{y}}_{3}=\mathrm{y}_{1} \mathrm{y}_{2}-\beta \mathrm{y}_{3}+\mathrm{u}_{3}
\end{aligned}
$$

where, $\mathrm{y}_{1}-\mathrm{y}_{3}$ are the state variables $\alpha, \beta, \gamma$ are unknown parameters of the system and $\mathrm{u}_{1}-\mathrm{u}_{3}$ are the nonlinear controls to be designed. The anti-synchronization error e is defined by:

$$
\begin{aligned}
& \mathrm{e}_{1}=\mathrm{y}_{1}+\mathrm{x}_{1} \\
& \mathrm{e}_{2}=\mathrm{y}_{2}+\mathrm{x}_{2} \\
& \mathrm{e}_{3}=\mathrm{y}_{3}+\mathrm{x}_{3}
\end{aligned}
$$

The error dynamics is easily obtained as:

$$
\begin{aligned}
& \dot{\mathrm{e}}_{1}=\alpha\left(\mathrm{y}_{2}-\mathrm{y}_{1}\right)+\mathrm{a}\left(\mathrm{x}_{2}-\mathrm{x}_{1}\right)+\mathrm{u}_{1} \\
& \dot{\mathrm{e}}_{2}=\gamma \mathrm{y}_{1}+\mathrm{cx}_{2}-\mathrm{y}_{1} \mathrm{y}_{3}-\mathrm{x}_{1} \mathrm{x}_{3}+\mathrm{u}_{2} \\
& \dot{\mathrm{e}}_{3}=-\beta \mathrm{y}_{3}-\mathrm{bx}_{3}+\mathrm{y}_{1} \mathrm{y}_{2}+\mathrm{x}_{1} \mathrm{x}_{2}+\mathrm{u}_{3}
\end{aligned}
$$

Let us now define the adaptive control functions $\mathrm{u}_{1}$ (t), $\mathrm{u}_{2}(\mathrm{t})$ and $\mathrm{u}_{3}(\mathrm{t})$ as:

$$
\begin{aligned}
& \mathrm{u}_{1}(\mathrm{t})=-\hat{\alpha}\left(\mathrm{y}_{2}-\mathrm{y}_{1}\right)-\mathrm{a}\left(\mathrm{x}_{2}-\mathrm{x}_{1}\right)-\mathrm{k}_{1} \mathrm{e}_{1} \\
& \mathrm{u}_{2}(\mathrm{t})=-\hat{\gamma} \mathrm{y}_{1}-\mathrm{cx}_{2}+\mathrm{y}_{1} \mathrm{y}_{3}+\mathrm{x}_{1} \mathrm{x}_{3}-\mathrm{k}_{2} \mathrm{e}_{2} \\
& \mathrm{u}_{3}(\mathrm{t})=\hat{\beta} \mathrm{y}_{3}+\mathrm{bx}_{3}-\mathrm{y}_{1} \mathrm{y}_{2}-\mathrm{x}_{1} \mathrm{x}_{2}-\mathrm{k}_{3} \mathrm{e}_{3}
\end{aligned}
$$

where, $\hat{\alpha}, \hat{\beta}$ and $\hat{\gamma}$ are estimates of $\alpha, \beta$ and $\gamma$, respectively and $k_{i}, i=1,2,3$ are positive constants. Substituting Eq. 31 into Eq. 30 the error dynamics simplifies to:

$$
\begin{aligned}
& \dot{\mathrm{e}}_{1}=(\alpha-\hat{\alpha})\left(\mathrm{y}_{2}-\mathrm{y}_{1}\right)-\mathrm{k}_{1} \mathrm{e}_{1} \\
& \dot{\mathrm{e}}_{2}=(\gamma-\hat{\gamma}) \mathrm{y}_{1}-\mathrm{k}_{2} \mathrm{e}_{2} \\
& \dot{\mathrm{e}}_{3}=-(\beta-\hat{\beta}) \mathrm{y}_{3}-\mathrm{k}_{3} \mathrm{e}_{3}
\end{aligned}
$$

Let us now define the parameter errors as:

$$
\begin{aligned}
& \mathrm{e}_{\alpha}=\alpha-\hat{\alpha} \\
& \mathrm{e}_{\beta}=\beta-\hat{\beta} \\
& \mathrm{e}_{\gamma}=\gamma-\hat{\gamma}
\end{aligned}
$$

Substituting Eq. 33 into Eq. 32, researchers obtain the error dynamics:

$$
\begin{aligned}
& \dot{\mathrm{e}}_{1}=\mathrm{e}_{\alpha}\left(\mathrm{y}_{2}-\mathrm{y}_{1}\right)-\mathrm{k}_{1} \mathrm{e}_{1} \\
& \dot{\mathrm{e}}_{2}=\mathrm{e}_{\gamma} \mathrm{y}_{1}-\mathrm{k}_{2} \mathrm{e}_{2} \\
& \dot{\mathrm{e}}_{3}=-\mathrm{e}_{\beta} \mathrm{y}_{3}-\mathrm{k}_{3} \mathrm{e}_{3}
\end{aligned}
$$

For the derivation of the update law for adjusting the estimates of the parameters, the Lyapunov approach is used. Researchers consider the quadratic Lyapunov function defined by:

$$
\mathrm{V}=\frac{1}{2}\left(\mathrm{e}_{1}^{2}+\mathrm{e}_{2}^{2}+\mathrm{e}_{3}^{2}+\mathrm{e}_{\alpha}^{2}+\mathrm{e}_{\beta}^{2}+\mathrm{e}_{\mathrm{\gamma}}^{2}\right)
$$

Which is a positive definite function on $\mathrm{R}^{6}$. Researchers also note that:

$$
\begin{aligned}
& \dot{\mathrm{e}}_{\alpha}=-\dot{\hat{\alpha}} \\
& \dot{\mathrm{e}}_{\beta}=-\hat{\hat{\beta}} \\
& \dot{\mathrm{e}}_{\gamma}=-\dot{\hat{\gamma}}
\end{aligned}
$$

Differentiating Eq. 35 along the trajectories of Eq. 34 and using Eq. 36, researchers obtain:

$$
\begin{aligned}
\dot{\mathrm{V}}= & -\mathrm{k}_{1} \mathrm{e}_{1}^{2}-\mathrm{k}_{2} \mathrm{e}_{2}^{2}-\mathrm{k}_{3} \mathrm{e}_{3}^{2}+\mathrm{e}_{\alpha}\left[\mathrm{e}_{1}\left(\mathrm{y}_{2}-\mathrm{y}_{1}\right)-\dot{\hat{\alpha}}\right] \\
& +\mathrm{e}_{\beta}\left[-\mathrm{e}_{3} \mathrm{y}_{3}-\dot{\hat{\beta}}\right]+\mathrm{e}_{\gamma}\left[\mathrm{e}_{2} \mathrm{y}_{1}-\dot{\hat{\gamma}}\right]
\end{aligned}
$$

In view of Eq. 37 the estimated parameters are updated by the following law:

$$
\begin{aligned}
& \dot{\hat{\alpha}}=\mathrm{e}_{1}\left(\mathrm{y}_{2}-\mathrm{y}_{1}\right)+\mathrm{k}_{4} \mathrm{e}_{\alpha} \\
& \dot{\hat{\beta}}=-\mathrm{e}_{3} \mathrm{y}_{3}+\mathrm{k}_{5} \mathrm{e}_{\beta} \\
& \dot{\hat{\gamma}}=\mathrm{e}_{2} \mathrm{y}_{1}+\mathrm{k}_{6} \mathrm{e}_{\lambda}
\end{aligned}
$$

where, $\mathrm{k}_{4}-\mathrm{k}_{6}$ are positive constants. Substituting Eq. 38 into Eq. 37, researchers get:

$$
\dot{\mathrm{V}}=-\mathrm{k}_{1} \mathrm{e}_{1}^{2}-\mathrm{k}_{2} \mathrm{e}_{2}^{2}-\mathrm{k}_{3} \mathrm{e}_{3}^{2}-\mathrm{k}_{4} \mathrm{e}_{\alpha}^{2}-\mathrm{k}_{5} \mathrm{e}_{\beta}^{2}-\mathrm{k}_{6} \mathrm{e}_{\gamma}^{2}
$$

Which is a negative definite function on $\mathrm{R}^{6}$. Thus, by Lyapunov Stability theory (23), it is immediate that the 


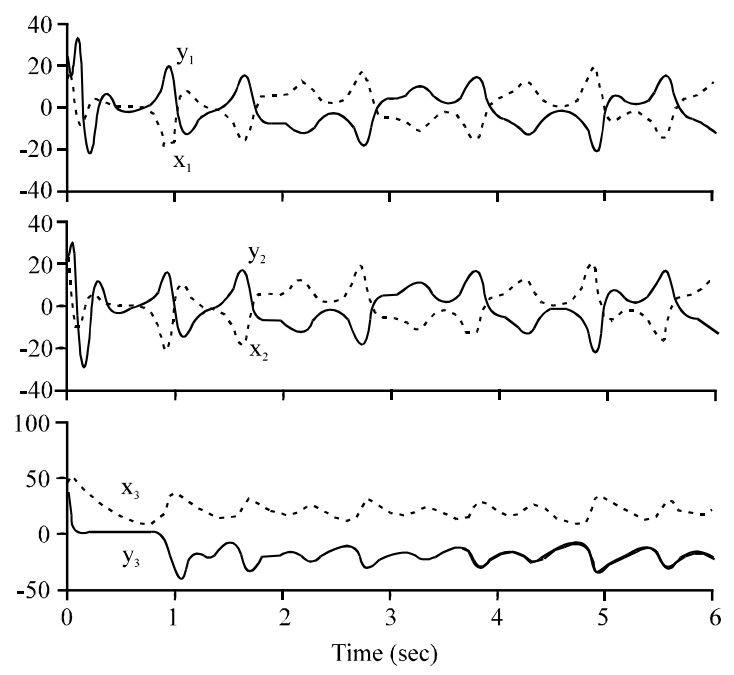

Fig. 7: Anti-synchronization of non-identical Lu and Pan system

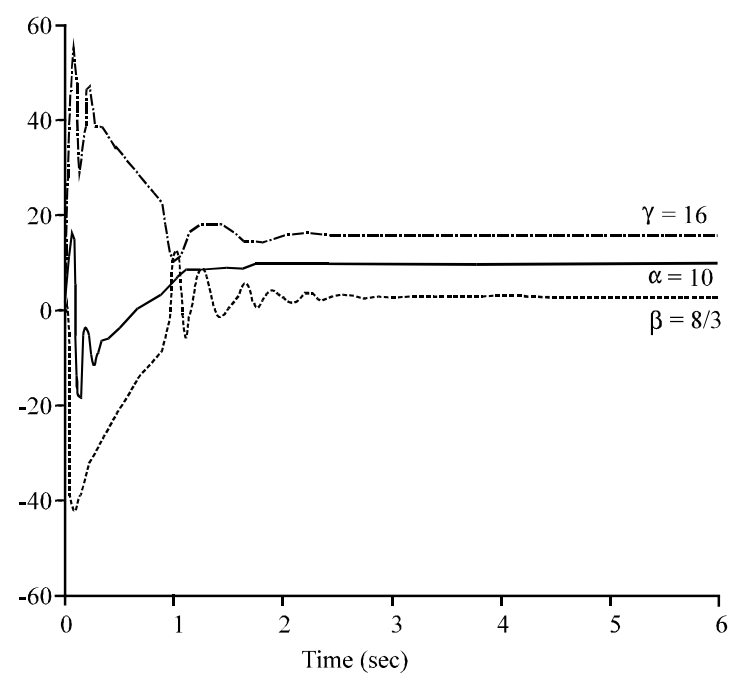

Fig . 8: Parameter estimates $\hat{\alpha}(t), \hat{\beta}(t), \hat{\gamma}(t)$

anti-synchronization error and parameter estimation error decay to zero exponentially with time. Hence, researchers have proved the following result.

Theorem 3: The non-identical Lu system 27 with known parameters and Pan system 28 with unknown parameters are globally and exponentially anti-synchronized by the adaptive control law 31 where the update law for the parameter estimates is given by 38 and $k_{i}, i=1, \ldots, 6$ are positive constants.

Numerical results: For the numerical simulations, the fourth-order Runge-Kutta method with time-step $\mathrm{h}=10^{-6}$ is used to solve the chaotic systems 27 and 28 with the adaptive control law 18 and the parameter update law 25 using MATLAB. For the chaotic systems 27 and 28 the parameter values are taken as those which result in the chaotic behaviour of the systems, viz.

$$
\begin{gathered}
a=36, b=3, c=20 \\
\alpha=10, \beta=8 / 3, \gamma=16
\end{gathered}
$$

Suppose that the initial values of the parameter estimates are:

$$
\hat{\alpha}(0)=2, \hat{\beta}(0)=8 \text { and } \hat{\gamma}(0)=5
$$

Suppose that the gain values are taken as:

$$
\mathrm{k}_{\mathrm{i}}=2 \text { for } \mathrm{i}=1,2, \ldots, 6
$$

The initial values of the master system 27 are taken as:

$$
x_{1}(0)=11, x_{2}(0)=26, x_{3}(0)=42
$$

The initial values of the slave system 28 are taken as:

$$
\mathrm{y}_{1}(0)=25, \mathrm{y}_{2}(0)=20, \mathrm{y}_{3}(0)=34
$$

Figure 7 shows the anti-synchronization of the nonidentical Lu system 27 and Pan system 28. Figure 8 shows that the estimated values of the parameters $\hat{\alpha}, \hat{\beta}$ and $\hat{\gamma}$ converge to the system parameters $\alpha=10, \beta=8 / 3$ and $\gamma=16$, respectively.

\section{CONCLUSION}

In this study, researchers have deployed adaptive control method to achieve global chaos antisynchronization of identical uncertain Lu and Chen (2002), systems identical uncertain Pan et al. (2010) systems and non-identical $\mathrm{Lu}$ and uncertain Pan systems. In adaptive anti-synchronization of identical chaotic systems, the parameters of the master and slave systems are unknown and we devise feedback control laws using estimates of the system parameters. In adaptive anti-synchronization of non-identical chaotic systems, the parameters of the master system are known but the parameters of the slave system are unknown and we devise feedback control laws using the estimates of the parameters of the slave system. The adaptive nonlinear control method is very useful in practical applications. The adaptive established using Lyapunov stability theory. Since, the Lyapunov exponents are not required for these calculations, the adaptive nonlinear control method is very effective and convenient to achieve global chaos anti-synchronization for the chaotic systems. Numerical simulations are also shown to demonstrate the effectiveness of the adaptive anti-synchronization results derived in this study. 


\section{REFERENCES}

Agiza, H.N. and M.T. Yassen, 2001. Synchronization of rossler and chen chaotic dynamical systems using active control. Phys. Lett. A, 278: 191-197.

Alligood, K.T., T. Sauer and J.A. Yorke, 1997. Chaos: An Introduction to Dynamical Systems, Springer-Verlag, New York.

Blasius, B., A. Huppert and L. Stone, 1999. Complex dynamics and phase synchronization in spatially extended ecological system. Nature, 399: 354-359.

Carroll, T.L. and L.M. Pecora, 1991. Synchronizing chaotic circuits. IEEE Trans. Circuits Syst., 38: 453-456.

Hahn, W., 1967. The Stability of Motion. Springer-Verlag, Berlin.

Han, S.K., C. Kerrer and Y. Kuramoto, 1995. Dephasing and bursting in coupled neural oscillators. Phys. Rev. Lett., 75: 3190-3193.

Huang, L., R. Feng and M. Wang, 2004. Synchronization of chaotic systems via nonlinear control. Phys. Lett. A, 320: 271-275.

Kocarev, L. and U. Parlitz, 1995. General approach for chaotic synchronization with application to communication. Phys. Rev. Lett., 74: 5028-5031.

Konishi, K., M. Hirai and H. Kokame, 1998. Sliding mode control for a class of chaotic systems. Phys. Lett. A, 245: 511-517.

Lakshmanan, M. and K. Murali, 1996. Chaos in Nonlinear Oscillators: Controlling and Synchronization. World Scientific, Singapore.

Liao, T.L. and S.H. Tsai, 2000. Adaptive synchronization of chaotic systems and its application to secure communications. Chaos Solitons Fractals, 11: $1387-1396$.
Lu, J. and G. Chen, 2002. A new chaotic attractor coined. Int. J. Bifurcation Chaos, 12: 659-661.

Murali, K. and M. Lakshmanan, 1998. Secure communication using a compound signal from generalized synchronizable chaotic systems. Phys. Lett. A, 241: 303-310.

Ott, E., C. Grebogi and J.A. Yorke, 1990. Controlling chaos. Phys. Rev. Lett., 64: 1196-1199.

Pan, L., D. Xu and W. Zhou, 2010. Controlling a novel chaotic attractor using linear feedback. J. Inform. Comput. Sci., 5: 117-124.

Park, J.H. and O.M. Kwon, 2003. A novel criterion for delayed feedback control of time-delay chaotic systems. Chaos Solitons Fractals, 17: 709-716.

Pecora, L.M. and T.L. Carroll, 1990. Synchronization in chaotic systems. Phys. Rev. Lett., 64: 821-824.

Sundarapandian, V., 2011 a. Global synchronization of LuChen-Cheng four-scroll systems by sliding mode control. Comput. Sci. Eng. Int. J., 1: 26-35.

Sundarapandian, V., 2011 b. Hybrid chaos synchronization of hyperchaotic newton-leipnik systems by sliding mode control. Int. J. Control Theor. Comput. Model., 1: $1-10$.

Sundarapandian, V., 2011c. Hybrid synchronization of liu-chen and tigan chaotic systems by active nonlinear control. Int. J. Adv. Sci. Technol., 3: 13-24.

Yang, T. and L.O. Chua, 1999. Control of chaos using sampled-data feedback control. Int. J. Bifurcation Chaos, 9: 215-219.

Yu, Y.G. and S.C. Zhang, 2006. Adaptive backstepping synchronization of uncertain chaotic systems. Chaos Solitons Fractals, 27: 1369-1375.

Zhang, $\mathrm{X}$. and $\mathrm{H}$. Zhu, 2008. Anti-synchronization of two different hyperchaotic systems via active and adaptive control. Int. J. Nonlinear Sci., 6: 216-223. 